\title{
Laboratuvar öz yeterlik ölçeği geliştirme çalışması
}

\section{Adem AKKUS*}

Öz: Laboratuvar Öz Yeterlik Ölçeği (LÖYÖ) taslak olarak likert tipli 15 maddeden oluşturulmuştur. Araştırmanın örneklemini sınıf öğretmenliği ve fen bilgisi öğretmenliği programında okuyan 248 öğrenci oluşturmaktadır. Açımlayıcı faktör analizi için orthogonal döndürme (varimax) tekniği ve principal axis factoring yöntemi kullanılmıştır. Faktör eigen değerleri paralel analiz ile kontrol edilmiş ve faktör sayılarına karar verilmiştir. Ölçeğin amacına hizmet etmeyen maddeler ölçekten çıkarılmış ve faktör analizi tüm ölçek maddeleri amaca hizmet edene değin tekrar yapılmıştır. Üçü olumsuz olmak üzere 10 maddeden ve iki faktörlü bir yapıdan oluşan LÖYÖ’nün Cronbach's alpha güvenirlik değeri .898'dir. İlk faktör “Laboratuvar olumlu beceri algısı” olarak isimlendirilmiş ve Cronbach’s alpha güvenirlik değeri .916’dır. İkinci faktör ise "Laboratuvar olumsuz beceri algısı" olarak adlandırılmış ve Cronbach's alpha güvenirlik değeri .711'dir.

Anahtar Kelimeler: Laboratuvar öz yeterlik, Öz yeterlik, Laboratuvar, Ölçek, Ölçek geliştirme,

\section{A Study of Developing Laboratory Self-Efficacy Scale}

Abstract: Draft laboratory self-efficacy scale consisted of 15 Likert type items. Sample of the study consists of 248 students who study at science education and classroom education programs. Exploratory factor analyses with orthogonal (varimax) rotation technique are carried out. Factor eigen values are checked with parallel analyses and number of factors are retained with respect to analyses results. Items which did not serve the purpose of the scale are excluded from the scale and factor analyses are carried out until it has been decided that all items in the scale serve the purpose. Scale consists of 10 items where 3 items are reverse coded items and has two factor structures. Scale internal consistency Cronbach’s alpha value is .898. First factor

\footnotetext{
* Dr. Öğr. Üyesi, Muş Alparslan Üniversitesi, Eğitim Fakültesi, Fen Bilgisi Öğretmenliği ABD, ademakkus@gmail.com ORCID: 0000-0001-9570-3582
} 
is named as "laboratory positive skills perception” with Cronbach’s alpha $=.916$ and second factor are named as “laboratory negative skill perception” with Cronbach’s alpha =.711.

Keywords: Laboratory self-efficacy, Self-efficacy, Laboratory, Scale, Scale development.

\section{Giriş}

Bilimsel bilginin önceki asırlara göre daha fazla olması doğal bir sonuç olarak daha fazla ürün ve gelişmeleri sağlamıştır. Ancak daha yoğun bilgi, onun daha iyi edinilmesi ve günlük yaşamla ilişkilendirilmesi ihtiyacını da önemli hale getirmektedir. Öğrencilerin günlük yaşama ilişkin bilgiyi kullanabilmeleri amacıyla çeşitli yöntemler denenmekte ve bilginin aktarılmasında gelişen teknolojinin de kullanılması önerilerinde bulunulmaktadır (Güngör ve Aşkar, 2004; Kıryak ve Özdilek, 2019). Bilginin yapılandırılmasında laboratuvar etkinlikleri de önem taşımaktadır. Laboratuvarlar özellikle öğrencilere soyut gelen konuların veya problem çözme becerilerinin işe koşularak hali hazırda ki konuların test edilmesi ve bilginin deneyimler aracılığıyla elde edilmesi için sıklıkla ve rahatlıkla kullanılabilmektedir. Yapılan araştırmalar derslerde laboratuvar kullanımının öğrencilerin başarısına katkı sağladığını, öğrencilerin bilimsel düşünce sistemini gerçekleştirmelerine yardımcı olduğunu ve öğrencilerin laboratuvarlara karşı olumlu tutum geliştirdiklerini göstermektedir (Açışlı ve Turgut, 2011; Kılıç, Keleş ve Uzun, 2015). Bu nedenle araştırmacılar öğrenme ortamları ve laboratuvarlara karşı tutumların ilişkisini araştırmaktadırlar (Musisi, 2018; Rummey, Clemons ve Spagnoli, 2019)

Bazı öğrencilerin laboratuvar derslerine karşı ilgiliyken diğerlerinin neden ilgili olmadığı öğrenme ortamları ve öğrencilerin laboratuvara karşı tutumları arasındaki ilişkilerle ortaya konmaya çalışılmaktadır (Kurbanoğlu, 2014). Öğrenmedeki bir diğer unsur ise öğretmen faktörüdür. Her ne kadar benzer tutumlara sahip olsalar da öğretmenleriyle olumlu ilişkilere sahip öğrencilerin öğrenme ortamını daha iyi algıladıkları tespit edilmiştir (Monsen, Ewing ve Kwoka, 2014). Bununla birlikte öğretmenin oluşturduğu öğrenme ortamının laboratuvara karş1 daha olumlu tutum geliştirdiği ve daha iyi öğrenmeyi sağladığı da tespit edilen bulgulardandır (Güneş, Şener, Topal Germi ve Can, 2013; Ural, 2016). Öğrenme ortamları ve tutumlar arasındaki ilişki araştırmacıların sıklıkla ilgisini çekmiş ve bu konuda çeşitli çalışmalar yapılmıştır. Bu çalışmalarda genelde ölçekler kullanılmıştır. Örneğin Lang, Wong ve Fraser (2005) kimya laboratuvarı öğrenme ortamını, öğretmen-öğrenci ilişkilerini ve öğrenci 
tutumlarını incelemiştir. Alkan ve Erdem (2013) ise kendi kendine öğrenmenin laboratuvarda başarı, hazır bulunuşluk, laboratuvar becerileri tutumu ve endişesi üzerine etkilerini incelemişlerdir. Ölçeklerin kullanılması araştırmacıların veya öğretmenlerin öğrenci tutumlarına ilişkin bilgi sahibi olmalarına, derslerin etkililiğini ve verimliliğini yordama, derslere veya çalışmalara yön vermelerini sağlamaktadır. Burada önemli olan ölçeklerin hangi amaçla kullanıldığı ve hangi amaca yönelik kullanılabileceğidir. Kullanılan ölçeklerin yapısal olarak ölçülmek istenen özelliği ölçmesi ve anlam karışıklığına yol açmaması gereklidir (Coll, Dalgety ve Salter, 2002).

Laboratuvarlar teorik konuların gerçek yaşamla ilişkilendirilebildiği yerler olmasından ötürü öğrencilerin bilişsel, duyuşsal ve psikomotor becerilerinin de gelişmesini sağlamaktadır. Laboratuvar etkinliklerinin öğrenci ilgi ve ihtiyaçlarını karşılaması durumunda öğrencilerin ilgili derse karşı daha motive oldukları ve etkinliklerde yer alma isteklerinin daha fazla olduğu bilinmektedir (Fraser ve Lee, 2008). Öğrencilerin derse daha ilgili olması, okul ve öğrenme ortamının daha olumlu algılanmasına ve doğal bir süreç olarakta öğrencilerin daha fazla çaba göstermelerini sağlamaktadır. Öğrencilerin belli bir tutuma sahip olmaları onların ilişkili duruma karşı da olumlu özellikler geliştirmelerini sağlamaktadır. Daha açık bir ifadeyle öğrencilerin belli bir derse karşı olumlu tutuma sahip olmaları onların o dersten daha başarılı olmasını da sağlamaktadır. Öğrencilerin derse karşı olumsuz tutuma sahip olmaları ise sınıf ve okul içi disiplin problemlerine yol açabilir ve hatta öğrencinin okulu terk etmesi sonucunu da doğurabilir (Eryılmaz, Yıldız ve Akın, 2011; Tekin, Sağır ve Karamustafaoğlu, 2012). Öğrencilerin sahip oldukları tutumlar ile öğrencilerin ortaya koydukları ürünler arasında ilişki bulunmaktadır (Wititsiri, 2007). Bu nedenle öğrencilerin laboratuvar derslerine karşı olumlu tutuma sahip olmalarının onların bilimsel bilgiye ve bilimsel düşünce sistemine ilişkin olumlu tutuma sahip olacakları ve bu doğrultuda düşünce sistemi geliştirecekleri varsayımını oluşturmaktadır. Bundan dolayı öğrencilerin sahip oldukları tutumların nedenlerinin bilinmesi en az tutumlar kadar önemlidir (Nuhoğlu ve Yalçın, 2004)

Tutumlar öğrencilerin derse karşı ilgili olması vb. davranışlar üzerinde etkilidir. Öğrencilerin derse karşı istekli olmaları akademik başarılarını etkileyen faktörlerden biridir. Öğrenci isteği derse devam, çalışmaya sebat ve motivasyonlarını etkileyen bir unsurdur (Devadoss ve Foltz, 1996). Tutumlar ve öz yeterlik algıları, davranışlar üzerinde etkili olmasından ötürü ilişkili kavramlardır. Bu nedenle araştırmacılar tarafından öz yeterlik kavramı da incelenmekte, öğrenciler ve eğitim üzerindeki etkisi araştırılmaktadır (Savran Gencer, Sevim 
ve Kaska, 2015). Bu araştırmalar öğrencilerin öz yeterlik algılarının yüksek olmasının, sahip oldukları tutumlar üzerinde olumlu etkisi olduğunu ve laboratuvar kullanımına yönelik öğrenci kaygılarını anlamlı düzeyde düşürdüğünü göstermektedir (Kurbanoglu ve Akim, 2010). Theory of Reasoned Action (Sebepli Eylem Teorisi) ve Theory of Planned Behavior (Planlı Davranış Teorisi) davranışları ve davranışların tutumlarla ilişkisini açıklamada başarı göstermiştir. $\mathrm{Bu}$ nedenle, davranışların değişiminde veya ortaya çıkmasında tutumların etkili olduğunu belirten bu teorilere göre davranışlar değiştirilebilir. Ancak bu değişikliğin ne şekilde ve ne kadar yapılacağının bilinmesi önemlidir. $\mathrm{Bu}$ ise bireylerin tutumlarına ilişkin bilgi sahibi olunduğunda yapılabilecek bir durumdur. Böylelikle tutumların ne kadarının ne yönde değişikliğe uğraması gerektiğine karar verilebilir ve gerekli davranış değişiklikleri sağlanabilir (Ajzen, 2005a; Madden, Ellen ve Ajzen, 1992; Teo ve Lee, 2010; Trafimow, 2009).

Öz yeterlik kavramı, tutumlardan etkilenmesi ve davranış değişikliklerine yol açması nedeniyle önem taşımaktadır. Öz yeterlik, bireyin bir şeyi yapabileceğine olan inancı anlamına gelmektedir (Karwowski ve Kaufman, 2017). Öz yeterlik inancı yüksek öğrenciler öğrenmelerinin sorumluluklarını alabilir, uzun ve kısa vadeli öğrenme hedeflerini belirleyebilir ve öğrenme stratejilerini geliştirebilirler (Zimmerman, Bonner ve Kovach, 1996). Yapılan bazı araştırmalar öz yeterlik algısının öğretmenler üzerinde de etkili olduğunu ortaya koymaktadır. Öz yeterlik algısı düşük öğretmenler yeni yöntemleri kullanmaktan kaçınmaktadırlar (Berg ve Smith, 2016; Bursal, 2010; Karabatak ve Turhan, 2017). Davranışlar temel olarak düşünceler etrafında şekillenir. Düşünceler ise deneyimler tarafından şekillendirilir. Tüm bunların bileşkesi ise öz yeterlik algısını oluşturur. Bireylerin öz yeterlik algıları içinde bulundukları etkinlikleri ve çevrelerini etkiler. Düşük öz yeterlik algısı, bireylerin görevlerini yerine getirmekten kaçınmalarına neden olur (Bandura, 2010). Öz yeterlik algısı kişisel ve kişiler arası inançlar, değer yargıları, dini inanışlar, sosyoekonomik düzey ve okul başarısına bağlı olarak da değişebilir (Bandura, 2006; Berg ve Smith, 2016). Bu nedenle birçok farklı öz yeterlik boyutundan bahsedilebilir. Örneğin öz yeterlik algısının alt boyutlarından biri yaratıcı öz yeterlik algısıdır (Jaussi ve Randel, 2014). Diğer öz yeterlik algılarına örnek olarak görev ve planlama öz yeterlikleri verilebilir. Her öz yeterlik belli bir durumla ilişkilidir. Örneğin görev öz yeterliği bireyin belli bir görevi yerine getirme öz yeterlik algısını tanımlarken, başa çıkma öz yeterliği ise bireyin belli bir görevi yerine getirirken zorluklarla başa çıkma becerisine olan güveni tasvir eder. Görev öz yeterliği bir işi başlatma için gerekliyken başa çıkma öz yeterliği o işin devamlılığı için gereklidir (Rodgers, Hall, Blanchard, McAuley ve Munroe, 2002). 
Öz yeterlik kavramının ilkeleri onun psikoloji, sağlık, tıp, sosyal politikalar, psikopatoloji, atletizm, işletme ve uluslararası ilişkiler gibi birçok farklı alanda kullanılmasını sağlamıştır. Bu durum, öz yeterliliğin en önemli özelliğinin birçok farklı boyuta sahip olmasının da bir göstergesidir. Bu nedenle bir öz yeterlik boyutunda yüksek değere sahip bir birey başka bir öz yeterlik boyutunda düşük değere sahip olabilir. Bundan dolayı, kullanılacak öz yeterlik ölçeklerinin etkili olabilmesi için ölçülmek istenen hedefe de uygun olması gerekir (Artino, 2012). Ölçekler ve anketler bu amaçla kullanılabilir (Deshpande, 2004; Francis, Eccles, Johnston, Walker, Grimshaw, Foy, Kaner, Smith ve Bonetti, 2004; Hinkin, 1998; Wong ve Lian, 2003) ve böylelikle amaca uygun biçimde bir eylem planı hazırlanabilir (Hinkin, 1998; Hinkin, Tracey ve Enz, 1997).

Eğitimde kullanılan öz yeterlik ölçekleri ise çoğunlukla genel öz yeterlik ölçekleridir ve bu nedenle yanlış biçimde kullanılmaktadır (Artino, 2012). Akademik veri tabanlarını arama kapasitesi özelliğinden dolayı Google Akademik "laboratory self efficacy" ve "laboratuvar öz yeterlik" anahtar kelimeleri kullanılarak İngilizce ve Türkçe kaynaklar tüm yıllar için araştırılmıştır. Yapılan araştırma neticesinde İngilizce yapılan çalışmalar incelendiğinde; Smist (1993) geliştirdiği bilimsel öz yeterlik ölçeğinin 4 faktörlü yapıda olduğunu ve bu faktörlerden birinin laboratuvar öz yeterlik faktörü olduğunu belirtmektedir. Miller (2006) kullandığ1 bilimsel öz yeterlik ölçeğinin üç faktörden oluştuğunu ve bu faktörlerden birinin laboratuvar öz yeterlik faktörü olduğunu belirtmektedir. Berkes (2007) biyoloji laboratuarı öz yeterlik algısı ve etkileri üzerine çalışmıştır. Boddey (2012) kimya öz yeterlik ölçeği geliştirmiş ve faktörlerden birisinin kimya laboratuarı öz yeterlik boyutu olarak ortaya çıktığını belirtmektedir. Shi, He, Wang ve Huan (2015) daha önceden hazırlanmış bir öz yeterlik ölçeğini laboratuvar öz yeterlik ölçeği şeklinde uyarlayarak kullanmışlardır. Musisi (2018) fen bilimlerinde öz yeterlik ve laboratuvar öz yeterlik algılarını ve etkilerini çalışmıştır. Rummey, Clemons ve Spagnoli (2019) ise kimya laboratuvarı endişesi ve öz yeterliğini bir arada çalışmışlardır. Alkan (2016) kimya laboratuvarı öz yeterlik ölçeği geliştirmiştir. Türkçe yapılan çalışmalar incelendiğinde ise Ekici (2009a) tarafından biyoloji öz yeterlik ölçeğinin Türkçe’ye uyarlandığı ve bu ölçeğin alt boyutlarından birinin laboratuvar öz yeterliği olduğu tespit edilmiştir. Sonrasında ise tekrar Ekici (2009b) tarafından biyoloji öğretmenlerine yönelik laboratuvar kullanımı öz yeterlik algılarının incelenmesi amacıyla bir ölçek geliştirilmiştir. Yapılan literatür taraması doğrultusunda her ne kadar laboratuvar tutum ve öz yeterlik üzerine yapılmış çalışmalar bulunsa da, laboratuvar öz yeterlik algısı üzerine yapılan Türkçe 
çalışmaların yeterli düzeyde olmadığı tespit edilmiştir. Dolayısıyla bu çalışmanın amacı geçerli ve güvenilir yeni bir Türkçe laboratuvar öz yeterlik ölçeği (LÖYÖ) geliştirmektir.

Bu nedenle bu araştırmanın problem durumu özgün bir laboratuvar öz yeterlik ölçeği (LÖYÖ) geliştirilebilir mi?

Alt problem durumları ise;

1. Örneklem sayısı LÖYÖ’yü geliştirmek için yeterli midir?

2. LÖYÖ faktörlerinin varyansları açıklama düzeyi uygun mudur?

3. LÖYÖ’nün faktör yapısı uygun mudur?

4. Faktör yük değerleri kabul edilebilir düzeyde midir?

5. LÖYÖ güvenilir bir ölçek midir?

6. LÖYÖ \%27 alt ve üst grupları ayırmada başarılı mıdır?

\section{Yöntem}

\section{Araştırma Deseni}

Laboratuvar öz yeterlik ölçeği geliştirmek amacıyla metodolojik araştırma yöntemi benimsenmiş ve bu çalışmada kullanılmıştır. Metodolojik araştırma yöntemi ölçek geliştirme ve uyarlama çalışmalarında veri elde etmeye ve analizlerine yönelik sıklıkla kullanılan bir araştırma yöntemidir (Madans, 2001). Hedeflenen amaca uygun biçimde maddelerin oluşturulması amacıyla ölçek hazırlamaya ilişkin literatür taraması yapılmış (Ajzen, 2005a; Ajzen, 2005b; Ajzen, 2005c; Friedman, Rodriguez ve McComb, 2001) ve bazı ana hatlar belirlenmiştir (Ajzen, 2005b; Brinkman, 2009; Cabrera-Nguyen, 2010; Deshpande, 2004; Francis vd., 2004; Hinkin, 1998; Hinkin vd., 1997; Hof, 2012; Johanson ve Brooks, 2010). Belirlenen bu ana hatlar;

a) Her hangi bir ikileme yol açmamak için kullanılan kelimelerin öğrencilerin şemasında yer almasına dikkat edilmelidir.

b) Soru maddeleri tek bir davranışı veya düşünceyi ölçmelidir.

c) Soru maddelerinin farklı biçimlerde yorumlanmaması için soyut tümcelerden kaçınılmalıdır.

d) Yönlendirme soruları kullanılmamalıdır.

e) Aynı cümle içinde iki olumsuz kelimenin kullanılmasından kaçınılmalıdır.

f) Soru tümceleri ölçülmek istenen alana yönelik olmalıdır. 
g) Soru maddelerinin sayısı cevaplayıcıların sıkılmayacağı kadar olmalıdır.

Araştırmada Thurstone eşit görünümlü aralıklar, semantik farkl1lıklar ve likert tipli ölçek tiplerinin amaçları ve kullanım esasları gözden geçirilmiştir. Hem daha kolay veri toplama hem de daha kolay genelleme yapabilme açısından likert tipli ölçeğin çalışmanın amacına hizmet ettiği düşünüldüğünden, oluşturulan ölçeğin likert tipli olmasına karar verilmiştir (Brinkman, 2009; Hof, 2012; Johanson ve Brooks, 2010; Lovelace ve Brickman, 2013). Ölçek bilgilendirme kısmında değerlendirmelerin kesinlikle katılmıyorum, katılmıyorum, kararsızım/fikrim yok, katılıyorum ve kesinlikle katılıyorum şeklinde yapılacağı belirtilmiştir. Ayrıca ölçek üzerinde kesinlikle katılmıyorum ifadesi 1, katılmıyorum ifadesi 2, kararsızım/fikrim yok ifadesi 3, katılıyorum ifadesi 4 ve kesinlikle katılıyorum ifadesi 5 rakamıyla tanımlanmıştır. Ölçek maddelerinin beşli likert tipte hazırlanmasının nedeni hem iç tutarlılık katsayısını arttırmak hem de yeterli varyansa ulaşmak hedefinin güdülmesidir (Ajzen, 2005b; Brinkman, 2009; Francis vd., 2004; Hinkin, 1998; Hinkin vd., 1997; Lovelace ve Brickman, 2013). Bazı cevaplayıcıların ölçek maddelerini hep aynı hizada işaretleme eğilimini ortadan kaldırmak amacıyla olumsuz ifadeler içeren ölçek maddeleri ölçek içerisinde cevaplayıcıların dikkatini sağlamak amacıyla uygun biçimde yerleştirilmiştir (Hinkin, 1998; Hof, 2012; Francis vd., 2004)

Örneklem: Ölçek geliştirme çalışmalarında literatürde genel olarak madde-cevaplayıcı oranı tavsiyesinin 1:2 ve 1:10 oranında değiştiği tespit edilmiştir (Anthoine, Moret, Regnault, Sébille ve Hardouin, 2014; Cabrera-Nguyen, 2010; Hinkin, 1998; Hinkin vd., 1997). Geliştirilen ölçeğin veri toplama aşaması 2017-2018 eğitim öğretim yılında müfredatında laboratuvar dersi bulunan eğitim fakültesindeki anabilim dallarında öğrenim gören ve en az bir laboratuvar dersi almış olan öğrencilere sunularak tamamlanmıştır. Bu amaç doğrultusunda çalışmaya gönüllü olan öğrencilerden fen bilgisi öğretmenliği 1, 2, 3 ve 4. sınıf düzeyinde ve sınıf öğretmenliği bölümünde öğrenim gören 2, 3 ve 4 sınıf düzeyinde öğrenim gören toplamda 248 lisans öğrencisine laboratuvar öz yeterlik ölçeği uygulanmıştır. Bu öğrencilerin 95’i fen bilgisi öğretmenliği bölümünde öğrenim görürken 153 öğrenci sınıf öğretmenliği bölümünde öğrenim görmektedir. Madde sayısı ve örneklem oranının 1:10 üstü olması nedeniyle de örneklem sayısının uygun olduğuna karar verilmiştir.

Laboratuvar Öz Yeterlik Ölçeği (LÖYÖ): Ölçek maddeleri literatür araştırması çerçevesinde şekillendirilmiştir. Geliştirilen ölçek alanında uzman ve ölçek geliştirme üzerinde çalışmaları 
bulunan üç öğretim üyesinin uzman görüşüne sunulmuş ve LÖYÖ’nün nihai şekli oluşturulmuştur. Geliştirilen LÖYÖ 15 maddeden oluşmakta ve dört ters kodlamalı maddeye sahiptir. Ters kodlamaya sahip maddeler LÖY6, LÖY10, LÖY12 ve LÖY15’tir. Oluşturulan LÖYÖ için çalışmaya gönüllü olan yedi (7) öğrenciyle pilot çalışma yapılmıştır. Buradaki ana amaç öğrencilerden gelen dönütlere göre LÖYÖ’nün çalışmasını kontrol etmek ve var olan aksaklıkları gidermektir (Hinkin vd., 1997). Ölçeğin son hali gözden geçirilmiş ve LÖY13’ün genel bir madde yerine özel bir durumu ölçen madde olması nedeniyle ölçekten çıkarılmasına karar verilmiştir. Bu durumda ölçeğin son hali 14 sorudan oluşmaktadır.

\section{Verilerin Analizi}

Ölçek geliştirme çalışmalarında ölçek maddelerinin oluşturulan ölçeğin ana amacını yansıtması arzu edilen durumdur. $\mathrm{Bu}$ nedenle elde edilen veriler aracılığıyla ölçeğin ilk güvenirlik hesaplamalarının yapılması ve güvenirliği düşüren maddelerin ölçekten çıkarılması tavsiye edilmektedir (Johnson ve Morgan, 2016). Sonrasında ise faktör yapılarını ortaya çıkarmak için principal axis faktör yöntemi ve orthogonal (varimax) döndürme tekniğinin kullanılması tavsiye edilmektedir (Field, 2013; Hof, 2012).

\section{Bulgular}

\section{İlk güvenirlik analizlerine ilişkin bulgular}

Veri analiz çalışmaları Cronbach's $\alpha$ ve faktör değerlerine göre yapılmış ve yapılan her işlem aşağıda ayrıntılı biçimde açıklanmıştır. Ölçeğin yapılan ilk iç tutarlılık analizinde Cronbach's $\alpha$ değeri =.838 olarak bulunmuştur. Bunun üzerine maddeler corrected-item total correlation değerlerine göre incelenmiş ve kabul edilebilir değerin (.2) altında kalan maddeler ölçekten çıkarılmıştır (Johnson ve Morgan, 2016). Bu doğrultuda LÖY4, LÖY7, LÖY11 ve LÖY15 iç güvenirlik katsayısını düşürmeleri nedeniyle ölçekten çıkarılmıştır. Bu durumda ölçek 10 maddeden oluşmaktadır ve ölçeğin son haline göre tekrar yapılan iç tutarlılık analiz sonucu Cronbach’s $\alpha$ değeri =.898 “yüksek derecede güvenilir” (Kalayc1, 2010) olarak tespit edilmiştir. Bu nedenle alt problemler doğrultusunda LÖYÖ’nün faktör yapısının incelenmesi amacıyla principal axis faktör yöntemi SPSS 25. programı aracılığıyla 10 madde için yapılmış ve orthogonal (varimax) döndürme tekniği kullanılmıştır. Böylelikle ölçek içerisinde meydana gelen faktörlerin tespitinin sağlanması ve oluşturulan ölçeğin daha doğru biçimde incelenmesi hedeflenmiştir

\section{Örneklem sayısının yeterliliğine ilişkin bulgular}


Kaiser-Meyer-Olkin test sonuçları $(\mathrm{KMO}=.906)$ kabul edilebilir değer olan .5'in (Field, 2013) üzerinde ve “iyi” (Kalaycı, 2010) olduğundan, örneklem sayısının analizler için yeterli olduğuna karar verilmiştir. Bartlett küresellik test sonuçları istatistiksel olarak anlamlı bulunduğundan $\left(x^{2}(45)=1437.444, \mathrm{p}=.00<.05\right)$ ve KMO değerleri örneklem sayısının yeterli olduğunu gösterdiğinden tüm ölçek maddeleri için analizler yapılmıştır.

\section{Faktörlerin varyansları açıklama düzeyine ilişkin bulgular}

Ortaya çıkan faktör yapılarının eigen değerlerini elde etmek amacıyla ilk analizler yapılmıştır. Yapılan ilk analizler sonucunda Kaiser kriter değeri 1'in üzerinde olan iki faktörlü bir yapının ortaya çıktığı tespit edilmiştir. Elde edilen eigen değerleri faktör 1 için 5,396 ve faktör 2 için 1,352'dir. İlk faktör varyansın \% 39,933’ünü oluştururken ikinci faktör varyansın $\%$ 18,911'ini oluşturmaktadır. Her iki faktörün toplamda varyansın \% 58,843'ünü oluşturduğu elde edilen bulgulardandır. Çok faktörlü desenler için açıklanan varyansın \%40 ile \%60 arasında olması yeterli olarak kabul edilir (Çokluk, Şekercioğlu ve Büyüköztürk, 2010). Bu nedenle açıklanan varyansın uygun olduğu tespit edilmiştir.

\section{Faktör yapısının uygunluğuna ilişkin bulgular}

Elde edilen faktör değerlerinin tutarlığının test edilmesi için paralel analiz yöntemi tavsiye edilmektedir (Field, 2013; Johnson ve Morgan, 2016). Bu nedenle paralel analiz testi için Monte Carlo PCA simülasyonları 1000 tekrarlı (Watkins, 2000) olarak yapılmış ve elde edilen eigen değerlerinin tutarlılığ incelenmiştir. Elde edilen eigen değerleri faktör 1 için 1,3250 ve faktör 2 için 1,2246'dır. Paralel analizler için yapılan Monte Carlo PCA simülasyonları eigen değerlerini doğruladığından scree plot (Resim 1) grafiğinin incelenmesine karar verilmiştir. 
Resim 1.

Scree Plot

Elde edilen scree plot, faktör analiz istatistiksel sonuçları, Kaiser'in eigen değerlerinin 1 olması koşulu ve paralel analiz eigen değerlerinin Kaiser değerlerini doğrulaması sonucunda oluşturulan ölçeğin (LÖYÖ) iki faktörlü bir yapıda olduğuna karar verilmiştir.

\section{Faktör yük değerlerinin uygunluğuna ilişkin bulgular}

Çok faktörlü desenlerde faktör yük değerlerinin kabul edilebilir düzeyde olması için .32 değerine sahip olması gerekmektedir (Çokluk, Şekercioğlu ve Büyüköztürk, 2010). Kalaycı (2010) ise .50 ve üzeri faktör yük değerlerinin oldukça iyi kabul edildiğini belirtmektedir. Bu nedenle faktör yük değerleri hesaplanarak ortak madde varyansları $\left(h^{2}\right)$ ile birlikte Tablo 1'de verilmiştir.

Tablo 1.

Ortak Madde Varyansları ve Faktör Yükleri

Maddeler $\quad h^{2} \quad$ Faktör yükleri

Faktör 1 Faktör 2

\begin{tabular}{lll}
\hline LÖY1 &, 746 &, 814 \\
LÖY2 &, 724 &, 800 \\
LÖY3 &, 514 &, 697
\end{tabular}




\begin{tabular}{llll} 
LÖY5 &, 689 &, 727 & \\
LÖY6 &, 725 & &, 802 \\
LÖY8 &, 405 &, 636 & \\
LÖY9 &, 694 &, 781 & \\
LÖY10 &, 444 & &, 591 \\
LÖY12 &, 298 & &, 544 \\
LÖY14 &, 646 &, 695 & \\
\hline
\end{tabular}

\section{Ölçek güvenirliğine ilişkin bulgular}

Literatür ışı̆̆ında, oluşan faktör yapılarının güvenirlik incelemesi yapılmıştır (Field, 2013; Francis vd., 2004). LÖYÖ iki faktörlü yapıdan oluşmakta ve ilk faktör toplamda 7 maddeden oluşmakta ve Cronbach's $\alpha$ güvenirlik değeri .916 “yüksek derecede güvenilir”, ikinci faktör ise 3 maddeden oluşmakta ve Cronbach's $\alpha$ güvenirlik değeri .711 "güvenilir”, olarak tespit edilmiştir. Ölçeğin tamamının Cronbach’s alpha güvenirlik değeri ise .898 “yüksek derecede güvenilir” olarak tespit edilmiştir (Kalaycı, 2010).

\section{Alt ve üst \%27 grupları ayırma gücüne ilişkin bulgular}

Geliștirilen ölçeğin daha detaylı biçimde incelenmesi amacıyla bağımsız örneklem t testi, örneklem grubunda yer alan öğrencilerin üst \%27 ve alt \%27 kısmında yer alan öğrenciler için her madde üzerinde yapılmıştır. Madde kodları (MK), yeni madde kodları (YMK), madde ortalamas1 (X), standart sapma (SS), corrected-item total correlation değerleri ve tüst-alt(\%27) sonuçları Tablo 2'de verilmiştir.

Tablo 2.

Item-Total Correlation ve tüst-alt(\%27) Sonuçları

\begin{tabular}{|c|c|c|c|c|c|}
\hline MK & YMK & $\mathrm{X}$ & SS & $\begin{array}{c}\text { Corrected-item total } \\
\text { correlation }\end{array}$ & $\mathrm{t}_{\text {üst-alt(}(\% 27)}$ \\
\hline LÖY1 & LÖY1 & 3,31 & 1,451 & .793 & $24,029 *$ \\
\hline LÖY2 & LÖY2 & 3,18 & 1,439 & .778 & $19,920 *$ \\
\hline LÖY3 & LÖY3 & 3,16 & 1,214 & .636 & $12,058 *$ \\
\hline LÖY5 & LÖY4 & 3,26 & 1,510 & .781 & $25,982 *$ \\
\hline LÖY6 & LÖY5 & 2,73 & 1,584 & .609 & $17,663 *$ \\
\hline LÖY8 & LÖY6 & 3,46 & 1,178 & .493 & 10,159* \\
\hline LÖY9 & LÖY7 & 3,35 & 1,301 & .772 & $20,698 *$ \\
\hline LÖY10 & LÖY8 & 2,62 & 1,234 & .548 & 11,794* \\
\hline LÖY12 & LÖY9 & 2,86 & 1,378 & .302 & 7,897* \\
\hline LÖY14 & LÖY10 & 3,25 & 1,492 & .761 & $20,960 *$ \\
\hline
\end{tabular}


Oluşturulan laboratuvar öz yeterlik ölçeği (LÖYÖ) toplamda 10 maddeden oluşmaktadır. Bu maddelerden LÖY5, LÖY8 ve LÖY9 Ters kodlu maddedirler (EK 1).

\section{Tartışma ve Sonuç}

Field (2013) ve Kalaycı (2010) KMO değerinin 1'e yakın olmasının örneklem sayısının yeterliliğini gösterdiğini belirtmektedirler. LÖYÖ, KMO değeri olarak .906 değerine sahip olduğundan geliştirilen ölçeğin örneklem sayısının yeterli olduğu tespit edilmiştir. Ayrıca Çokluk, Şekercioğlu ve Büyüköztürk (2010) sosyal bilimler için çok faktörlü desenlerde açıklanan varyansın \%40 ile \%60 arasında olmasının yeterli olduğunu belirtmektedirler. LÖYÖ'nün ilk faktörü varyansın \%39,933'ünü açıklarken ikinci faktörü varyansın \%18,911'ini açıklamaktadır. Her iki faktör toplamda varyansın \%58,843'ünü açıklarken \%60 değerine son derece yakın bir değer oluşturmaktadır. Bu nedenle LÖYÖ’nün sosyal bilimler için kabul edilebilir varyansları açıklama düzeyine sahip olduğu tespit edilen bulgulardandır.

Araştırmanın 3. ve 4. alt problemleri olan faktör yük değerleri ve faktör yapısı incelendiğinde LÖYÖ’nün güçlü bir faktör yapısına sahip olduğu ortaya çıkmaktadır. Ölçek geliştirme çalışmalarında eigen değeri 1 ve üstü olan yapılar geçerli faktörler olarak kabul edilir. Ancak bazı araştırmacılar eigen değerlerinin 1 olarak referans alınması halinde gerçekte var olandan daha fazla faktör yapısının kabul edilebileceği hususunda uyarılarda bulunmaktadırlar. Bundan ötürü faktör yapılarının doğrulanmasında paralel analiz yönteminin daha doğru sonuçlar vereceği hususunda tavsiyelerde bulunmaktadırlar (Field, 2013; Johnson ve Morgan, 2016). Bu çalışmada LÖYÖ’nün faktör yapısı paralel analiz yöntemiyle doğrulanmış, scree plot grafiğgi (Resim 1) ile de faktör yapısının doğruluğu tekrar teyit edilmiştir. Ayrıca faktör yük değerleri incelendiğinde birinci faktör için en düşük değerin .636 ikinci faktör içinse .544 olduğu tespit edilmiştir (Tablo 1). Bu değerler kabul edilebilir değer olan .3 ve .4 değerlerinin üstünde ve oldukça iyi değerler olarak kabul edilmektedir (Çokluk, Şekercioğlu ve Büyüköztürk, 2010; Field, 2013; Johnson ve Morgan, 2016; Kalayc1, 2010). Ortaya çıkan iki faktörlü yapı ve bu faktörlere ait maddeler incelendiğinde ilk faktörün laboratuvar olumlu beceri algısı olarak adlandırılabileceği düşünülmektedir. Faktör 2'nin altında yer alan maddelerin olumsuz maddeler olması ise dikkat çekici bir durumdur. $\mathrm{Bu}$ durumda ikinci faktörün ise laboratuvar olumsuz beceri algısı olarak adlandırılabileceği düşünülmektedir. Her iki faktör ve altında yer alan maddeler incelendiğinde, yeteneklerine güvenen ve kendi becerilerine ilişkin olumlu algılara sahip olan öğrencilerin diğer öğrencilere kıyasla daha iyi akademik başarı sergileyeceği düşünülmektedir. Chan (2002) kendi yeteneklerine 
güven(e)meyen bireylerin bilimsel süreç becerilerini işlemede yetersiz kalabildiklerini belirtmektedir. Benzer biçimde Tighezza (2014)'da öğrencilerin kendi yeteneklerine ilişkin algılarının akademik başarıyla pozitif yönde ilişkili olduğunu ortaya koymuştur.

Smist (1993), Miller (2006) ve Boddey (2012)’in çalışmaları incelendiğinde kullandıkları öz yeterlik ölçeklerinin çok faktörlü yapıda olduğu ve bu faktörlerden birinin laboratuvar öz yeterlik faktörü olduğu tespit edilmiştir. LÖYÖ ise sadece laboratuvar öz yeterlik ölçeği olarak geliştirilmiş ve bu amaç doğrultusunda güvenilir ve geçerli bir araç olduğunu istatistiksel analizler sonucunda göstermiştir. Berkes (2007) ve Ekici (2009a; 2009b) tarafından geliştirilen laboratuvar öz yeterlik ölçeklerinin biyoloji laboratuvarı kullanımına yönelik olduğu, bununla birlikte Shi vd. (2015)’nin genel bir fen laboratuvarı öz yeterlik algısı üzerine çalıştıkları tespit edilmiştir. Bu durumda LÖYÖ’nün hem genel bir fen laboratuvarı öz yeterlik ölçeği olması ve bu özelliğinden ötürü literatürde bulunan diğer laboratuvar öz yeterlik ölçeklerinden ayrılması hem de tek boyutlu bir yapıda oluşturularak sadece laboratuvar öz yeterlik algılarını ölçmek amacıyla geliştirilmesi LÖYÖ’nün farklılığını ortaya koymaktadır.

Literatür 1şı̆̆ında bazı araştırmacılar ölçek geliştirme çalışmalarında, geliştirilen ölçeğin güvenirlik değerinin ve sonrasında ise madde ayırıcılığının alt ve üst \%27’lik gruplar için incelenmesi gerektiğini ifade etmektedirler (Francis vd., 2004; Moore ve Foy, 1997). LÖYÖ iki faktörlü yapıdan oluşmaktadır. İlk faktör Cronbach's $\alpha$ güvenirlik değeri .916'ya “yüksek derecede güvenilir”, ikinci faktör ise Cronbach's $\alpha$ güvenirlik değeri .711'e “güvenilir” sahiptir. Ölçeğin tamamının Cronbach’s alpha güvenirlik değeri ise .898 “yüksek derecede güvenilir” olarak tespit edilmiştir (Kalaycı, 2010). Bu durumda LÖYÖ’nün son derece güvenilir bir ölçek olduğu savunulabilir. Ayrıca ölçekte yer alan maddelerin tümü alt ve üst \%27'lik dilimde ayırt edicilik gücünü (Tablo 2) ortaya koymuştur. Bu durumda ölçek maddelerinin hem laboratuvar öz yeterlik algılarını ölçmede hem de alt ve üst \%27 grupları ayırt edicilikte başarılı olduğu rahatlıkla söylenebilir.

Ölçek ve ölçek maddelerinin daha ayrıntılı bir biçimde tartışılabilmesi için t değerleri incelenmiştir. En yüksek t değeri LÖY4 (25,982) ve LÖY1 (24,029)'de oluşmuştur. Bu durumda öğrenciler çalışmaları ve emek harcamaları halinde (LÖY4) emeklerinin karşılığını alacaklarına ve bunun not olarak karşılık (LÖY1) bulacağına dair algıya sahiptirler. Nitekim en yüksek $\mathrm{t}$ değerlerine sahip diğer ölçek maddeleri incelendiğinde LÖY2 (19,920), LÖY7 $(20,698)$ ve LÖY10 $(20,960)$ sonuçları bu durumu doğrulamaktadır. Laboratuvar da kendinden 
istenen şeyleri rahatlıkla öğreneceğini düşünen (LÖY2) bir öğrenci, deneyleri başarıyla gerçekleştireceğini (LÖY7) ve laboratuvar dersinde yüksek not alacağını (LÖY1) düşünmektedir. En düşük $\mathrm{t}$ değerlerinin ortaya çıktığı ölçek maddeleri incelendiğinde bu düşüncenin doğrulandığı söylenebilir. Yeteneklerine güven(e)meyen öğrenci (LÖY9; 7,897) ders başarısını sağlayacağı konusunda şüphe duymakta (LÖY6; 10,159) ve doğal olarak derslerden iyi notlar alacağını da düşünmemektedir. Bu durum LÖY3 $(12,058)$ ve LÖY8 $(11,794)$ sonuçlarında da ortaya çıkmaktadır. Kendini diğer öğrencilerden daha düşük seviyede (LÖY8) gören öğrenci yeteneklerine güvenmemekte ve doğal bir sonuç olarak diğer öğrencilere kıyasla ortaya daha iyi bir ürün koyabileceğini (LÖY3) düşünmemektedir. Kılıç, Keleş ve Uzun (2015) öğretmenlerle yaptıkları çalışmada öğretmenlerin laboratuvar kullanımında öz yeterlilik algılarının yükseltilmesi durumunda, öğretmenlerin hem bireysel hem de grup çalışmalarında daha fazla başarı gösterdiklerini belirtmektedirler. Laipply (2004) öz yeterlik ve bilime ilişkin tutum arasında pozitif yönde bir ilişki bulunduğunu belirtirken ders öğretmeninin, öğrencilerin olumlu tutum geliştirmesinde ve öz yeterlik algılarının yükselmesinde etkili olduğunu belirtmektedir. Uzuntiryaki ve Çapa Aydın (2009) kimya öz yeterlik ölçeği geliştirdikleri çalışmalarında ölçeklerinin üç boyutta öz yeterlilik faktörüne sahip olduğunu belirtmektedirler. $\mathrm{Bu}$ faktörler bilişsel davranışlar, psikomotor beceriler ve günlük yaşama yönelik öz yeterlik faktörleridir. $\mathrm{Bu}$ nedenle öz yeterlik algısının yüksek olmasının öğrencilerin bilişsel gelişimlerine olumlu katkıda bulunacağı ve Laboratuvar becerilerinin artabileceği savunulabilir. Erdem (2015) kimya öğretmen adaylarıyla yapmış olduğu çalışmasında kimya laboratuvarına karşı olumlu tutuma sahip öğrencilerin aynı zamanda olumlu öz yeterlik algılarına sahip olduğunu, öz yeterlik ve olumlu tutum arasında pozitif yönde olumlu bir ilişkinin bulunduğunu tespit etmiştir. Davranışı şekillendirmek bireylerin kendilerine ilişkin algılarını değiştirmek aracılığıyla mümkündür. $\mathrm{Bu}$ nedenle davranış değişikliğinin gerçekleştirilebilmesi için kişilerin algılarını bilmek önemlidir (Ajzen, 2005a).

Sonuç olarak bu çalışmada geliştirilmiş olan LÖYÖ’nün literatüre katkı sağlayacak bir ölçek olduğu ve LÖYÖ’nün geliştirme süreçlerinin ayrıntılı biçimde izah edilmesinin, benzer çalışmaları yürütecek araştırmacılara katkı sağlayacağı düşünülmektedir. Araştırmacılar ve öğretmenler geliştirilmiş olan LÖYÖ’yü öğrencilerin durumlarını belirlemek için kullanabilir ve sonuçlara göre derslerinde çeşitli düzenlemeler yapabilirler.

\section{Makalenin Bilimdeki Konumu}

Matematik ve Fen Bilimleri Eğitimi Bölümü/Fen Bilgisi Eğitimi 


\section{Makalenin Bilimdeki Özgünlüğ̈̈}

Literatür taraması doğrultusunda Laboratuvar öz yeterlik ölçeği geliştirme ve var olan ölçekleri eğitimde kullanma üzerine çeşitli çalışmaların yapıldığı tespit edilmiştir. Ancak yapılan çalışmalar incelendiğinde Türkçe yapılan çalışmaların neredeyse çok az olduğu uluslararası yapılan çalışmaların ise yetersiz olduğu tespit edilmiştir. Bu nedenle Laboratuar öz yeterlik ölçeğinin geliştirilerek eğitimde kullanılması üzerine bir çalışma yapılmıştır.

\section{Kaynaklar}

Açışlı, S. ve Turgut, Ü. (2011). Fizik laboratuvar uygulamalarında 5E öğrenme modeline uygun olarak geliştirilen materyallerin öğrenci kazanımlarına etkisinin incelenmesi. International Online Journal of Educational Sciences, 3 (2), 562-593.

Ajzen, I. (2005a). Behavioral interventions based on the theory of planned behavior: Brief description of the theory of planned behavior.

http://people.umass.edu/aizen/pdf/tpb.intervention.pdf Erişim Tarihi: Kasım 2016

Ajzen, I. (2005b). Constructing a theory of planned behavior questionnaire: Brief description of the theory of planned behavior.

http://people.umass.edu/aizen/pdf/tpb.measurement.pdf Erişim Tarihi: Kasım 2016

Ajzen, I. (2005c). Sample TpB questionnare.

http://people.umass.edu/aizen/pdf/tpb.questionnaire.pdf Erişim Tarihi: Kasım 2016

Alkan, F., ve Erdem, E . (2013). Kendi kendine öğrenmenin laboratuvarda başarı, hazır bulunuşluk, laboratuvar becerileri tutumu ve endişeye etkisi. Hacettepe Üniversitesi Eğitim Fakültesi Dergisi, 44 (44) , 15-26

Anthoine, E., Moret, L., Regnault, A., Sébille, V., ve Hardouin, J.-B. (2014). Sample size used to validate a scale: a review of publications on newly-developed patient reported outcomes measures. Health and Quality of Life Outcomes, 12, 2.

Artino, A.R. (2012). Academic self-efficacy: from educational theory to instructional practice. Perspectives on Medical Education, 1, 76-85. 
Bandura, A. (2006). Guide for constructing self-efficacy scales. Self-efficacy beliefs of adolescents, 5, 307-337. Urdan, T., ve Pajares, F. (Eds.). Greenwich, CT: IAP.

Bandura, A. (2010). Self-Efficacy. The corsini encyclopedia of psychology.

Berg, D.A.G ve Smith, L.F. (2016). Preservice teacher self-efficacy beliefs: An opportunity to generate "good research" in the asia-pacific region. In S.G Editor ve D. P. Editor (Eds.), Asia-Pacific Perspectives on Teacher Self-Efficacy (1-17). Rotterdam: Sense Publishers

Berkes, E. (2007). Practicing biology: Undergraduate laboratory research, persistence in science, and the impact of self-efficacy beliefs. Unpublished Doctorate Thesis. Graduate School of Arts and Sciences of Washington University, Missouri, USA.

Bernardez, R.Q. (1982). Factors affecting attitudes to laboratory work [Abstract]. Unpublished Thesis. Baguio City, Philippines.

Boddey, K. (2012). Chemistry experiences of first-year nursing students: the interplay of self efficacy, anxiety, prior chemistry experience and academic performance-a mixed method approach. Unpublished Master Thesis. Avondale College of Higher Education, Auckland, New Zealand.

Brinkman, W-P. (2009). Design of a questionnaire instrument, handbook of mobile technology research methods. ISBN 978-1-60692-767-0, pp. 31-57 Netherlands: Nova Publisher

Cabrera-Nguyen, P. (2010). Author guidelines for reporting scale development and validation results in the Journal of the Society for Social Work and Research. Journal of the Society for Social Work and Research, 1 (2), 99-103.

Chan, M.T. (2002). The teaching of science process skills: Primary teachers' self-perception [Abstract]. Asia-Pacific Journal of Teacher Education \& Development, 5 [special 1], 91-111.

Coll, R.K., Dalgety, J., ve Salter, D. (2002). The development of the chemistry attitudes and experiences questionnaire (CAEQ). Chemistry Education Research and Practice in Europe, 3 (1), 19-32. 
Çokluk, Ö., Şekercioğlu, G. ve Büyüköztürk, Ş. (2010). Sosyal bilimler için çok değişkenli istatistik spss ve lirsel uygulamaları. APegem Akademi. Ankara

Deshpande, L. (2004). Challenges in measurement of scientific attitude. Paper presented at epiSTEME-1: An International Conference to Review Research on Science Technology and Mathematics Education (137-138), Goa, India.

Devadoss, S., ve Foltz, J. (1996). Evaluation of factors influencing student class attendance and performance. American Journal of Agricultural Economics, 78 (3), 499-507.

Ekici, G. (2009a). Biyoloji öz-yeterlik ölçeğinin Türkçe’ye uyarlanması. Kastamonu Eğitim Dergisi, 17 (1), 111-124.

Ekici, G. (2009b). Biyoloji öğretmenlerinin laboratuar kullanımı öz-yeterlik algılarının incelenmesi. Ahi Evran Üniversitesi Ĕ̈itim Fakültesi Dergisi, 10 (3), 25-35.

Erdem, E. (2015). The relationship between self-efficacy and attitudes of chemistry teacher candidates. Problems of Education in the $21^{\text {st }}$ Century, 63, 62-70.

Eryılmaz, A., Y1ldı, İ., ve Akın, S. (2011). Investigating of relationship between attitudes towards physics laboratories, motivation and amotivation for the class engagement. Eurasian Journal of Physics and Chemistry Education, Special Issue, 59-64.

Field, A. (2013). Discovering statistics using ibm spss statistics ( $4^{\text {th }}$ Edition). London: SAGE

Francis, J., Eccles, M. P., Johnston, M., Walker, A. E., Grimshaw, J. M., Foy, R., Kaner, E. F. S., Smith, L. and Bonetti, D. (2004). Constructing questionnaires based on the theory of planned behaviour: A manual for health services researchers. Newcastle upon Tyne, UK: Centre for Health Services Research, University of Newcastle upon Tyne.

Fraser, B. J., ve Lee, S. S. U. (2008). Science laboratory classroom environments in Korean high schools. Learning Environments Research, 12 (1), 67-84.

Friedman, P., Rodriguez, F., ve McComb, J. (2001). Why students do and do not attend classes. College Teaching, 49 (4), 124-133. 
Güneş, M.H., Şener, N., Topal Germi, N., ve Can, N. (2013). Fen ve teknoloji dersinde laboratuvar kullanımına yönelik öğretmen ve öğrenci değerlendirmeleri. Dicle Üniversitesi Ziya Gökalp Ĕ̈itim Fakültesi Dergisi, 20, 1-11.

Güngör,C., ve Aşkar, P. (2004). E-öğrenmenin ve bilişsel stilin başarı ve internet öz yeterlik algısı üzerindeki etkisi. Hacettepe Üniversitesi Eğitim Fakültesi Dergisi, 27, 116-125.

Hinkin, T. R. (1998). A brief tutorial on the development of measures for use in survey questionnaires. Organizational Research Methods, 2 (1), 104-121

Hinkin, T. R., Tracey, J. B., ve Enz, C. A. (1997). Scale construction: Developing reliable and valid measurement instruments. Journal of Hospitality \& Tourism Research, 21 (1), 100-120.

Hof, M.W. (2012). Questionnaire evaluation with factor analysis and cronbach's alpha : an example. http://www.let.rug.nl/nerbonne/teach/rema-stats-meth seminar/student-papers/MHof-QuestionnaireEvaluation-2012-Cronbach FactAnalysis.pdf Erişim Tarihi: Nisan 2018

Jaussi, K. S., ve Randel, A. E. (2014). Where to Look? Creative Self-Efficacy, Knowledge Retrieval, and Incremental and Radical Creativity. Creativity Research Journal, 26 (4), 400-410.

Johanson, G.A., ve Brooks, G.P. (2010). Initial scale development: Sample size for pilot studies. Educational and Psychological Measurement, 70 (3), 394-400.

Johnson, R.L. ve Morgan, G.B. (2016). Survey scales: Investigating scale quality. New York, NY: The Guilford Press.

Kalaycı, Ş. (2010). Spss uygulamalı çok değişkenli istatistik teknikleri. (5. Bask1). Asil Yayın Dağıtım Ltd. Şti. Ankara.

Karwowski, M. ve Kaufman, J.C. (Eds.). (2017). The creative self. San Diego, CA: Academic Press.

Kılıç, D., Keleş, Ö., ve Uzun, N. (2015). Fen bilimleri öğretmenlerinin Laboratuvar kullanımına yönelik öz yeterlik inançları: Laboratuvar uygulamaları programının etkisi. Erzincan Üniversitesi Eğitim Fakültesi Dergisi, 17 (1), 218-236. 
Kıryak, Z. ve Özdilek, Z. (2019). Tahmin-açıklama-gözlem-açıklama yönteminin sekizinci sınıf öğrencilerinin asit yağmurları konusundaki kavramsal anlama düzeylerine etkisi. Mehmet Akif Ersoy Üniversitesi Eğitim Fakültesi Dergisi, 51, 216-240.

Kurbanoğlu, N.İ. (2014). Lise öğrencilerinin kimya laboratuarı kaygı ve kimya dersi tutumlarının cinsiyet ve okul türü değişkenlerine göre incelenmesi. Eğitim ve Bilim, 39 (171), 199-210.

Kurbanoglu, N.I., ve Akim, A. (2010). The relationships between university students’ chemistry laboratory anxiety, attitudes and self-efficacy beliefs. Australian Journal of Teacher Education, 35 (8), 48-59.

Laipply, R.S. (2004). A case study of self-efficacy and attitudes toward science in an inquiry based biology laboratory. Unpublished Doctorate Thesis. The Graduate Faculty of The University of Akron, USA.

Lang, Q.C., Wong, A.F.L. ve Fraser, B.J. (2005). Student perceptions of chemistry laboratory learning environments, student-teacher interactions and attitudes in secondary school gifted education classes in Singapore. Research in Science Education, 35, 299-321.

Lovelace, M. and Brickman, P. (2013). Best practices for measuring students' attitudes toward learning science. CBE-Life Sciences Education, 12 (4), 606-617.

Madans, J. H. (2001). Health Surveys. International Encyclopedia of the Social \& Behavioral Sciences, 6619-6627.

Madden, T. J., Ellen, P. S., ve Ajzen, I. (1992). A comparison of the theory of planned behavior and the theory of reasoned action. Personality and Social Psychology Bulletin, 18 (1), 3-9.

Miller, M.D. (2006). Science self-efficacy in tenth grade Hispanic female high school students. Unpublished Doctorate Thesis. College of Education, University of Central Florida, USA

Monsen, J.J., Ewing, D.L., ve Kwoka, M. (2014). Teachers’ attitudes towards inclusion, perceived adequacy of support and classroom learning environment. Learning Environments Research, 17, 113-126 
Moore, R.W. \& Foy, R.L.H. (1997). The scientific attitude inventory: A revision (SAI II). Journal of Research in Science Teaching, 34 (4), 327-336.

Musisi, M. (2018). Gender, science self-efficacy and science related career aspirations among ordinary level students in Wakiso District. Unpublished Masters Dissertation. Makerere University, Kampala, Uganda

Nuhoğlu, H., ve Yalçın, N. (2004). Fizik laboratuvarına yönelik bir tutum ölçeğinin geliştirilmesi ve öğretmen adaylarının fizik laboratuvarına yönelik tutumlarının değerlendirilmesi. Gazi Üniversitesi Kırşehir Eğitim Fakültesi, 5 (2), 317-327.

Rodgers, W. M., Hall, C. R., Blanchard, C. M., McAuley, E., ve Munroe, K. J. (2002). Task and scheduling self-efficacy as predictors of exercise behavior. Psychology \& Health, 17 (4), 405-416.

Rummey, C., Clemons, T. D., ve Spagnoli, D. (2019). The impact of several demographic factors on chemistry laboratory anxiety and self-efficacy in students' first year of university. Student Success, 10 (1), 87-98.

Savran Gencer, A., Sevim, S., ve Kaska, A. (2015). Genel biyoloji laboratuvarında VEE diyagramı uygulaması: Fen bilgisi öğretmen adaylarının akademik başarılarının, öz yeterlik inançlarının ve tutumlarının boylamsal olarak değerlendirilmesi. Elektronik Sosyal Bilimler Dergisi, 14 (52), 183-202.

Shi, W-Z., He, X., Wang, Y. ve Huan, W. (2015). Effects of lab group sex composition on physics learning. Eurasia Journal of Mathematics, Science \& Technology Education, $11(1), 87-92$.

Smist, J.M. (1993). General chemistry and self-efficacy. Paper presented at the National Meeting of the American Chemical Society (206th, Chicago, IL, August 1993).

Tekin, S., Sağır, Ş.U., ve Karamustafaoğlu, S. (2012). Sınıf öğretmeni adaylarının fen bilgisi laboatuvar uygulamaları-1 dersi kazanımlarının kimya deneyleri açısından incelenmesi. Pamukkale Üniversitesi Eğitim Fakültesi Dergisi, 31, 163-174.

Teo, T. ve Lee, C. B. (2010). Examining the efficacy of the theory of planned behavior (TPB) to understand pre-service teachers' intention to use technology. In C.H. Steel, 
M.J. Keppell, P. Gerbic ve S. Housego (Eds.), Curriculum, technology \& transformation for an unknown future. Proceedings ascilite Sydney 2010 (pp.968-972) http://ascilite.org.au/conferences/sydney10/procs/Teo-concise.pdf Erişim Tarihi: Şubat 2018

Tighezza, M. (2014). Modeling relationships among learning, attitude, self-perception, and science achievement for grade 8 Saudi students. International Journal of Science and Mathematics Education, 12 (4), 721-740.

Trafimow, D. (2009). The theory of reasoned action. Theory \& Psychology, 19 (4), 501518.

Ural, E. (2016). The effect of guided-inquiry laboratory experiments on science education students' chemistry laboratory attitudes, anxiety and achievement. Journal of Education and Training Studies, 4 (4), 217-227

Uzuntiryaki, E., ve Çapa Aydın, Y. (2009). Development and validation of chemistry self efficacy scale for college students. Research in Science Education, 39 (4), 539-551.

Watkins, M. W. (2000). Monte carlo PCA for parallel analysis [computer software]. State College, PA: Ed \& Psych Associates.

Wititsiri, S. (2007). Students' learning outcomes and perceptions of the learning environments in physical chemistry laboratory classes in Thailand [Abstract]. Unpublished Doctorate Thesis, Science and Mathematics Education Center, Curtin University of Technology, Thailand.

Wong., M. ve Lian, S. (2003). Development of a self-efficacy scale for assessing secondary school students' science self-efficacy beliefs. http://citeseerx.ist.psu.edu/viewdoc/summary?doi=10.1.1.472.8479 Erişim Tarihi: Ekim 2014

Zimmerman, B.J., Bonner, S. ve Kovach, R. (1996). Developing self-regulated learners: Beyond achievement to self-efficacy. Washington, DC: American psychological association.

\section{EKLER}

\section{Ek 1.}


Laboratuvar Öz Yeterlik Ölçeği (LÖYÖ)

\begin{tabular}{|c|l|c|c|c|c|c|}
\hline & L ÖYÖ & $\mathbf{1}$ & $\mathbf{2}$ & $\mathbf{3}$ & $\mathbf{4}$ & $\mathbf{5}$ \\
\hline $\mathbf{1}$ & Laboratuvar derslerinde yüksek not alacağıma inanıyorum & $\mathbf{1}$ & $\mathbf{2}$ & $\mathbf{3}$ & $\mathbf{4}$ & $\mathbf{5}$ \\
\hline $\mathbf{2}$ & Laboratuvar derslerinde benden istenen şeyleri rahatlıkla öğrenirim & $\mathbf{1}$ & $\mathbf{2}$ & $\mathbf{3}$ & $\mathbf{4}$ & $\mathbf{5}$ \\
\hline $\mathbf{3}$ & Deneyleri diğer öğrencilerden daha iyi yapacăı̆ıma inanıyorum & $\mathbf{1}$ & $\mathbf{2}$ & $\mathbf{3}$ & $\mathbf{4}$ & $\mathbf{5}$ \\
\hline $\mathbf{4}$ & Daha fazla çalışırsam deneylerde başarııı olurum & $\mathbf{1}$ & $\mathbf{2}$ & $\mathbf{3}$ & $\mathbf{4}$ & $\mathbf{5}$ \\
\hline $\mathbf{5}$ & Laboratuvar ders notumun yüksek olacağını düşünmüyorum & $\mathbf{1}$ & $\mathbf{2}$ & $\mathbf{3}$ & $\mathbf{4}$ & $\mathbf{5}$ \\
\hline $\mathbf{6}$ & Laboratuvar sınavlarında yüksek not alacağıma eminim & $\mathbf{1}$ & $\mathbf{2}$ & $\mathbf{3}$ & $\mathbf{4}$ & $\mathbf{5}$ \\
\hline $\mathbf{7}$ & Deneyleri başarıyla yapacağımı düşünüyorum & $\mathbf{1}$ & $\mathbf{2}$ & $\mathbf{3}$ & $\mathbf{4}$ & $\mathbf{5}$ \\
\hline $\mathbf{8}$ & Sınıf arkadaşlarıma göre daha iyi bir öğrenci sayıımam & $\mathbf{1}$ & $\mathbf{2}$ & $\mathbf{3}$ & $\mathbf{4}$ & $\mathbf{5}$ \\
\hline $\mathbf{9}$ & Deneylerde başarısız olacağıma inanıyorum & $\mathbf{1}$ & $\mathbf{2}$ & $\mathbf{3}$ & $\mathbf{4}$ & $\mathbf{5}$ \\
\hline $\mathbf{1 0}$ & Laboratuvar dersinde öğrendiklerimi bir arkadaşıma da rahatılıkla & & & & \\
\hline
\end{tabular}

\section{Summary}

\section{Statement of Problem}

Laboratory activities are crucial in transforming abstract knowledge into tangible knowledge. Researches have already shown that laboratory activities help students in transforming knowledge and gain academic achievement alongside with positive attitude toward laboratories (Açışlı and Turgut, 2011; Kılıç, Keleş and Uzun, 2015). Education environments and their relationship with attitudes have been constantly studied. Scales are mainly used for this purpose since it provides easy data gather and generalization feature. For that reason, scales must target the right domain and reveal the interest of research (Coll, Dalgety and Salter, 2002). Attitudes are closely related with self-efficacy thus researchers investigate relationship of these two concepts and their effect on each other (Savran Gencer, Sevim and Kaska, 2015). It is important to use laboratory self-efficacy scales to determine the attitudes of students toward laboratory. However, it is revealed by the literature research that there are not enough studies on laboratory self efficacy scales. Also, studies indicate that general selfefficacy scales are used in education settings which in return cause wrong usage of the scales (Artino, 2012). For that aim, purpose of this study is to develop a new laboratory self-efficacy scale.

\section{Method}

Guidelines are determined with respect to literature research (Ajzen, 2005a; Ajzen, 2005b; Ajzen, 2005c; Brinkman, 2009; Cabrera-Nguyen, 2010; Deshpande, 2004; Francis et.al., 2004; Friedman, Rodriguez and McComb, 2001; Hinkin, 1998; Hinkin et.al., 1997; Hof, 
2012; Johanson and Brooks, 2010; ), and it is determined that a likert type scale would be beneficial for the purpose of the study. Scale consists of 5 degree likert type. By doing that it is ensured that internal consistency and sufficient variances will be obtained (Ajzen, 2005b; Brinkman, 2009; Francis et.al., 2004; Hinkin, 1998; Hinkin et al., 1997; Lovelace and Brickman, 2013). Since some respondents tend to choose the option at the edges, reversed coded sentences are used to trigger the vigilance of the respondents (Hinkin, 1998; Hof, 2012; Francis et.al., 2004). Literature review indicated that item respondent ratio changes between 1:2 to 1:10 (Anthoine, Moret, Regnault, Sébille and Hardouin, 2014; Cabrera-Nguyen, 2010; Hinkin, 1998; Hinkin et al., 1997). Created scale is applied to 248 students who were studying at science education and classroom education departments. Sampling method of the study is convenience sampling.

\section{Findings}

Exploratory factor analyses (EFA) and parallel analyses are done to determine the number of the factors within the scale. Initial reliability analysis revealed that scale's internal consistency Cronbach's $\alpha$ value is $=.838$ so, items which have the corrected-item total correlation value below the desired value (.2) are omitted from the scale (Johnson and Morgan, 2016). Final internal consistency of Cronbach's $\alpha$ value is $=.898$ which is highly reliable (Kalayc1, 2010).

Principal axis factoring method is used for 9 items through SPSS program with orthogonal (varimax) rotation technique. Kaiser-Meyer-Olkin test result $(\mathrm{KMO}=.906)$ is above the acceptable limit of .5 (Field, 2013). Bartlett sphericity test results confirmed significant $\left(\mathrm{x}^{2}(45)=1437.444, \mathrm{p}=.00<.05\right)$. EFA revealed there are two factors. First factor has eigenvalue of 5,396 and share \% 39,933 of the variance. Second factor has eigenvalue of 1,352 and share \% 18,911 of the variance. Two factors share \% 58,843 of the variance. Monte Carlo PCA for Parallel analysis is carried out to confirm factor eigen values and it is regarded that scale has two factors. Scree plot is given in Figure 1. Communalities and factor loadings of the items are given in Table 1. First factor has 7 items and has Cronbach's $\alpha$ value .916 and second factor has 3 items and has Cronbach's $\alpha$ value .711. (Field, 2013; Johnson and Morgan, 2016; Watkins, 2000). Independent samples t test is carried out for each item for the \%27 groups and it is revealed that each item has its discrimination power between $t_{\text {up-down(\%27). Item coding, new }}$ item coding, item means, standard deviation and corrected-item total correlation values are given in Table 2. 


\section{Discussion and Conclusion}

All the items in the scale proved its discrimination power between up and high \% 27 (Table 2). Two factors emerged within the scale. When items under the factors are examined then it may be regarded that first factor could be named as "positive perception on skills" and second factor could be named as "negative perception on skills". It is also noteworthy to mention that scale only has three reverse coded items and those items are placed under factor 2 which is negative perception on skills. When two factors are examined carefully it is understood that students who have confidence in their skills also have positive perception on their ability and hence could perform better academic achievement. Chan (2002) reports that students who do not have confidence in their ability cannot process scientific thinking mechanism. Similarly, Tighezza (2014) also reports students’ positive image on their ability has also positive effect on their academic achievement. 